\title{
Development and description of measurement properties of an instrument to assess treatment burden among patients with multiple chronic conditions
}

Viet-Thi Tran ${ }^{1,2}$, Victor M Montori ${ }^{3}$, David T Eton ${ }^{3}$, Dan Baruch ${ }^{4}$, Bruno Falissard ${ }^{5,6}$ and Philippe Ravaud 1,2,7* $^{*}$

\begin{abstract}
Background: Patients experience an increasing treatment burden related to everything they do to take care of their health: visits to the doctor, medical tests, treatment management and lifestyle changes. This treatment burden could affect treatment adherence, quality of life and outcomes. We aimed to develop and validate an instrument for measuring treatment burden for patients with multiple chronic conditions.
\end{abstract}

Methods: Items were derived from a literature review and qualitative semistructured interviews with patients. The instrument was then validated in a sample of patients with chronic conditions recruited in hospitals and general practitioner clinics in France. Factor analysis was used to examine the questionnaire structure. Construct validity was studied by the relationships between the instrument's global score, the Treatment Satisfaction Questionnaire for Medication (TSQM) scores and the complexity of treatment as assessed by patients and physicians. Agreement between patients and physicians was appraised. Reliability was determined by a test-retest method.

Results: A sample of 502 patients completed the Treatment Burden Questionnaire (TBQ), which consisted of 7 items ( 2 of which had 4 subitems) defined after 22 interviews with patients. The questionnaire showed a unidimensional structure. The Cronbach's $\alpha$ was 0.89 . The instrument's global score was negatively correlated with TSQM scores $\left(r_{s}=-0.41\right.$ to -0.53$)$ and positively correlated with the complexity of treatment $\left(r_{s}=0.16\right.$ to 0.40$)$. Agreement between patients and physicians $(n=396)$ was weak (intraclass correlation coefficient $0.38(95 \%$ confidence interval 0.29 to 0.47$)$ ). Reliability of the retest ( $n=211$ patients) was 0.76 ( 0.67 to 0.83 ).

Conclusions: This study provides the first valid and reliable instrument assessing the treatment burden for patients across any disease or treatment context. This instrument could help in the development of treatment strategies that are both efficient and acceptable for patients.

Keywords: chronic disease/therapy, patient participation, physician-patient relations, quality of life, questionnaires, workload

\section{Background}

Chronic diseases are the leading cause of mortality in the world, representing more than 36 million deaths in 2008 [1]. About $45 \%$ of the population and $88 \%$ of people older than 65 years have at least one chronic condition. The prevalence of chronic diseases continues to increase: in 2020, nearly $50 \%$ of the US population will have at least one

\footnotetext{
* Correspondence: philippe.ravaud@htd.aphp.fr

${ }^{1}$ Université Paris Descartes, Faculté de Médecine, Paris, France

Full list of author information is available at the end of the article
}

chronic condition [2]. Therefore, the challenge for physicians has switched from curing acute illnesses to managing multiple chronic conditions. However, illnesses are still the primary focus of medical care [3] and many clinical practice guidelines focus on single conditions. For example, a physician following extant guidelines could prescribe up to 12 medications for a patient with osteoporosis, osteoarthritis, type 2 diabetes mellitus, hypertension, and chronic obstructive pulmonary disease [4].

\section{C) Biomed Central}

(C) 2012 Tran et al; licensee BioMed Central Ltd. This is an Open Access article distributed under the terms of the Creative Commons Attribution License (http://creativecommons.org/licenses/by/2.0), which permits unrestricted use, distribution, and reproduction in any medium, provided the original work is properly cited. 
Being a patient implies more investment of time and effort than just taking medicines. It also involves drug management, self-monitoring, visits to the doctor, laboratory tests and changes of lifestyle. For example, patients with type 2 diabetes controlled by oral agents could spend 143 minutes daily in recommended self-care [5]. This workload can affect quality of life as severely as the illness itself, and patients rate this treatment burden equal to that of diabetic neuropathy or nephropathy [6].

Treatment burden can be defined as the impact of health care on patients' functioning and well-being, apart from specific treatment side effects $[7,8]$. It takes into account everything patients do to take care of their health: visits to the doctor, medical tests, treatment management, and lifestyle changes. Treatment burden is associated, independently of illnesses, with adherence to therapeutic care $[9,10]$ and could affect hospitalization [11] and survival rates [12].

Minimally disruptive medicine seeks to tailor treatment to the contexts of patients by integrating the notion of treatment burden in their care [13]. Therefore, caregivers need tools to establish the weight of the treatment burden. Many instruments assess treatment burden for specific conditions [14-18], but none has been developed to assess this burden globally across multiple chronic diseases. Because the treatment burden grows from the combination of chronic diseases, only an instrument that assesses it globally could help clinicians and researchers develop effective therapeutic programs that minimize the treatment workload [13].

In the present work, we aimed to develop a measure of treatment burden for patients with at least one chronic condition. This measure should be of use in daily clinical practice and in clinical research.

\section{Methods}

We used a multistep method to develop a tool to measure the treatment burden of chronic diseases $[19,20]$ following the quality criteria proposed in the literature [21].

\section{Stage 1: elaboration of the questionnaire}

The objective of the instrument was to capture the perception of treatment burden of patients as 'the work of being a patient' dealing with increasingly complex treatment regimens [13], that is, the impact of the workload of healthcare on a patient's well-being and functioning.

We searched MEDLINE via PubMed for literature on treatment burden and existing questionnaires assessing it in specific diseases. We found no instrument appraising the treatment burden globally. Treatment burden was often assessed only as a subscale of specific disease scales [14-17] and thus was considered only for the regimen associated with a particular condition. Items often focused on drug intake, adherence to care and convenience of use.

Using this literature review, three members of the team who had experience in the care of patients with chronic diseases (V-TT, BF, PR) highlighted possible relevant topics to capture the aspects of the workload of healthcare that could affect a patient's life. These topics were the burden associated with taking medicines, self-surveillance, laboratory tests, doctor visits, need for organization, administrative tasks, following advice on diet and physical exercise and social impact of the treatment. According to the conceptual model of our instrument, we chose not to include other consequences of the treatment such as treatment side effects.

In addition, because our instrument was elaborated in France and administered to French patients, we did not take into account the financial burden of treatment, because our national public health insurance program guarantees healthcare free of charge for patients with chronic conditions.

We recruited a convenience sample of 22 patients with at least 1 chronic condition from the department of internal medicine of Hospital Pitié-Salpetrière and a general practitioner clinic in Paris in April 2011 (Additional file 1, Appendix 1). These two settings involved patients with various chronic conditions, requiring primary, secondary and tertiary care. During semistructured interviews, we presented the concept of treatment burden to patients and asked them about their diseases, their treatment and the burden of treatment, with open-ended questions: 'Could you tell us about your health problems?' 'Could you tell us about what you have to do to take care of your health?' 'What aspects of your care have the most impact on your life?' Then, we asked them about the burden associated with the different topics highlighted earlier by asking them (1) to rate each of these items, (2) to explain why they would rate it like that and (3) if they found the item relevant in the assessment of treatment burden generally. Finally, we asked patients, if other aspects of the workload of healthcare bothered them. As a result of these interviews, examples were added to the items, and we added one item 'Frequent healthcare reminds me of my health problems' to the questionnaire.

The resulting questionnaire consisted of seven items (two of which had four subitems), formed by an introductory sentence with examples, followed by a rating scale ranging from 0 to 10 with numbers placed under boxes and labeled end anchors ('No burden' and 'Considerable burden') [22-24].

A group of ten physicians (two methodologists, three general practitioners, two internists, one cardiologist, one pneumologist, one diabetologist) with experience in the care of patients with chronic conditions, some of whom 
had experience in questionnaire development, reviewed the clarity and wording of the items. All physicians agreed that, on the surface, items appeared to be measuring what they actually were and that the instrument achieved face validity.

\section{Stage 2: measurement properties of the instrument}

The measurement properties of the questionnaire were assessed by four steps: (1) reduction of the number of items, (2) assessment of factorial validity, (3) assessment of construct validity and (4) assessment of reliability.

We recruited consecutive patients from six teaching hospitals of the Assistance-Publique Hôpitaux de Paris and eight general practitioner clinics in Paris to validate the questionnaire. Patients were eligible if they were 18 years or older, were able to complete a consent form and had at least one condition requiring medical follow-up for at least 6 months. Patients with cognitive impairment that could interfere with understanding the questionnaire were excluded. All patients provided written informed consent to be in the study.

Reducing the number of items was based on (1) a floor effect, considered present if more than $15 \%$ of respondents had the lowest score [21]; (2) the relevance of the items, assessed by the number of answers for which patients checked 'Does not apply'; and (3) item redundancy, suspected when interitem correlations by Spearman's correlation coefficient were $>0.80$ [19]. Items were eliminated after discussion among three investigators (V-TT, BF, PR).

Answers to the questionnaire were aggregated in a global score by summing the item responses. 'Does not apply' or missing answers were considered the lowest possible score (0) because we considered that a patient not concerned by a domain of the treatment burden had no burden for that domain.

Factorial validity was assessed by determining the dimensional structure of the questionnaire by use of factor analysis. Scree plots were used to visualize a break between factors with large and small Eigenvalues. Factors that appeared before the horizontal break were assumed to be meaningful. Internal consistency was assessed by Cronbach's $\alpha$ [25] and was considered acceptable between 0.70 and 0.95 [26].

Construct validity was obtained by confirming two constructs theorized on the treatment burden [27]. First, we hypothesized a negative correlation between treatment burden, defined as the work of dealing with complex treatment regimens, and treatment satisfaction, defined as the balance between expectations about the treatment, side effects, convenience of use, and perceived efficacy. Treatment satisfaction was assessed by the Treatment Satisfaction Questionnaire for Medication (TSQM), an 11-item questionnaire validated in a population with diverse chronic conditions, measuring patient satisfaction with various medications designed to treat, control or prevent a wide variety of medical conditions $[28,29]$. TSQM scores range from 0 to 100 and measure patient satisfaction with the treatment's effectiveness, side effects, convenience and globally. Correlations were expected to be higher between our instrument and the TSQM convenience score because some items overlapped. Second, we assumed a positive correlation between the patient evaluation of the treatment burden and treatment workload evaluated by items on (1) drug intake (number of tablets, injections and intakes per day); (2) medical follow-up (number of different physicians, medical appointments per month and hospitalizations per year); and (3) daily time spent on selfcare. The correlations between the global questionnaire score, the TSQM scores and treatment workload variables were assessed by Spearman correlation coefficient $\left(\mathrm{r}_{\mathrm{s}}\right)$ and considered high with $r_{s}>0.50$ and moderate with $r_{s} 0.35$ to 0.50 [30]. Wilcoxon and Kruskal-Wallis tests were used to compare measurements for qualitative variables across groups. A $P$ value $<0.05$ was considered statistically significant. We used linear regression analyses to examine variables that predicted the global questionnaire score. Relationships were characterized with beta coefficients, standard errors, and percent variance explained (adjusted $\mathrm{R}^{2}$ ) within these models. Heteroskedasticity was corrected by the method described by Greene et al. [31].

Description of our sample was completed by clustering homogenous groups of patients depending on the similarity of their response patterns to the Treatment burden questionnaire and analysis of treatment workload variables in each cluster of patients. Clustering involved a hierarchical ascendant classification with a Ward's distance method [32]. The number of clusters was determined so as to have a minimal sample of 100 patients. Stability of clustering was assessed by a twofold crossvalidation method.

We compared the patient's self-evaluation of treatment burden with an evaluation by their physician and by an informal caregiver using the same questionnaire adapted for heteroevaluation. Physicians and informal caregivers were asked to make the best estimate of the patient's treatment burden from their perspective.

Reliability of the instrument was determined by a testretest method. Patients completed the new instrument twice: at baseline and after 2 weeks or 1 month. Reliability was assessed by the intraclass correlation coefficient (ICC) for agreement [33]. The 95\% confidence intervals (95\% CIs) were determined by a bootstrap method. Agreement was considered acceptable with ICC $>0.60[27,34]$. Agreement was represented by Bland and Altman plots, which represent the differences between two measurements against the means of the two measurements [35].

Statistical analyses involved use of SAS v. 9.2 (SAS Institute, Cary, NC, USA) and R v. 2.13.1 http://www.r-project. 
org/. This study was approved by the Institutional Review Board of Hospital Bichat (IRB: 00006477).

\section{Results}

In total, 502 patients (mean age $59.3( \pm 17)$ years; 266 women $(53.1 \%)$ ) were included to validate the questionnaire from April 2011 to September 2011 in France; 257 were inpatients $(51.2 \%)$ and 300 reported a symptomatic disease (62.6\%) (Table 1). Self-reported main chronic conditions ranged from diabetes (16.5\%) to cancers $(6.9 \%)$ and included well controlled psychiatric illnesses (1.6\%).

During item reduction, we eliminated the subitem 'The conditions to store your medications (in your refrigerator etc.)' because a large number of patients responded 'Does

Table 1 Demographic and clinical characteristics of patients $(n=502)$

\begin{tabular}{|c|c|c|}
\hline Patient characteristics & Value & Missing data \\
\hline Age, years (range) & 60 (19 to 94) & 2 \\
\hline Female sex, no. (\%) & $266(53.1 \%)$ & 1 \\
\hline Marital status, no. (\%): & & 13 \\
\hline Married & $216(44.2 \%)$ & \\
\hline Live-in partner & $38(7.8 \%)$ & \\
\hline Single/separated & $171(35.0 \%)$ & \\
\hline Widowed & $64(13.1 \%)$ & \\
\hline Highest education level, no. (\%): & & 44 \\
\hline No diploma/primary school & $85(18.6 \%)$ & \\
\hline Secondary/high school & $195(42.6 \%)$ & \\
\hline College & $178(38.9 \%)$ & \\
\hline Inpatient, no. (\%) & $257(51.2 \%)$ & \\
\hline Duration of disease, years (range) & 10 (0 to 91 ) & 33 \\
\hline Presence of daily symptoms, no. (\%) & $300(62.6 \%)$ & 23 \\
\hline Need for assistance, no. (\%) & $132(26.4 \%)$ & 2 \\
\hline Hospitalizations during the last 12 months, no. (\%) & $0(0$ to 15$)$ & 40 \\
\hline Medical appointments/month, no. (\%) & $1(0$ to 30$)$ & 16 \\
\hline Different physicians, no. (\%) & $2(0$ to 10$)$ & 18 \\
\hline Tablets/day, no. (\%) & $4(0$ to 30$)$ & 14 \\
\hline Drug intakes/day, no. (\%) & $2(0$ to 6$)$ & 26 \\
\hline Injections/day, no. (\%) & $0(0$ to 8$)$ & 78 \\
\hline Diet, no. (\%) & $198(40.3 \%)$ & 11 \\
\hline Physical therapy, no. (\%) & $113(22.9 \%)$ & 9 \\
\hline Oxygen therapy, no. (\%) & $22(4.4 \%)$ & 4 \\
\hline Need for a specific organization for daily care, no. (\%) & $338(67.3 \%)$ & \\
\hline Time needed to organize drugs/week ${ }^{a}$ & $60 \min (0$ to $21 \mathrm{~h})$ & \\
\hline Need for self-monitoring, no. (\%) & $168(33.47 \%)$ & \\
\hline Time needed for self-monitoring/week ${ }^{a}$ & $60 \mathrm{~min}(0$ to $12 \mathrm{~h})$ & \\
\hline Presence of side effects, no. (\%) & $168(36.3 \%)$ & 39 \\
\hline Main chronic condition, no. (\%): & & 11 \\
\hline Diabetes & $81(16.5 \%)$ & \\
\hline Rheumatologic diseases & $59(12.0 \%)$ & \\
\hline High blood pressure and dyslipidemia & $44(9.0 \%)$ & \\
\hline Systemic diseases & $43(8.8 \%)$ & \\
\hline Pulmonary diseases (other than asthma) & $40(8.1 \%)$ & \\
\hline Heart diseases & $37(7.5 \%)$ & \\
\hline Asthma & $37(7.5 \%)$ & \\
\hline Cancers and hematological malignancy & $34(6.9 \%)$ & \\
\hline HIV infection & $19(3.9 \%)$ & \\
\hline Arterial or venous thrombosis & $17(3.5 \%)$ & \\
\hline Other diseases ${ }^{\mathrm{b}}$ & $80(16.3 \%)$ & \\
\hline
\end{tabular}

${ }^{a}$ Median time needed for concerned patients (self-reported)

bOther diseases include diseases of the digestive system, psychiatric diseases, allergies, non-malignant hemopathy, neurological diseases, sequelae of injury, and endocrine diseases (other than diabetes). 
not apply' (51.6\%) and it had a large floor effect (64.0\%) (Additional file 2, Appendix 2). Therefore, the final version of the questionnaire, the Treatment Burden Questionnaire (TBQ), consisted of seven items (two of which had four subitems) (Table 2).

Factorial validity, assessed by scree plots, favored a unidimensional instrument because $91 \%$ of the variance was explained by the first principal factor (Figure 1 and Additional file 3, Appendix 3). Cronbach's $\alpha$ was 0.89 . The global score of the Treatment Burden Questionnaire was the sum of the answers to each item and ranged from 0 to 130. It was highly correlated with every item of the questionnaire $\left(r_{\mathrm{s}}=0.47\right.$ to 0.68$)$ (Additional file 4, Appendix 4).

Construct validity showed (1) a moderate negative correlation of the Treatment Burden Questionnaire score with the TSQM global and convenience scores $\left(\mathrm{r}_{\mathrm{S}}=-0.41\right.$ and $\left.\mathrm{r}_{\mathrm{S}}=-0.53\right)$ and a weak negative correlation with the TSQM efficacy score $\left(\mathrm{r}_{\mathrm{S}}=-0.26\right)$ (Table 3$)$ and (2) a significant association of scores for variables used to describe treatment workload and the Treatment Burden Questionnaire global score (Table 4).

Using hierarchical ascendant classification, we clustered our sample in three homogenous groups of patients by the answers to the Treatment Burden Questionnaire (Additional file 5, Appendix 5). Twofold cross validation showed stable clustering results. The global score was $11.3( \pm 9.2)$ in the first cluster, $34.6( \pm 11.1)$ in the second cluster and $65.8( \pm 18.1)$ in the third cluster. Therefore, we defined the clusters as patients with low, moderate and high burden of treatment. Descriptive analysis of the treatment workload items within the three clusters showed that scores for these variables were significantly higher for patients with high treatment burden (Table 5). Treatment workload variables could explain up to $69 \%$ of the variability in the patient's score. Prediction of global score with these variables was more accurate with high than low treatment burden $\left(R^{2}=0.86\right.$ vs $\left.R^{2}=0.62\right)$ (Additional file 6, Appendix 6). Treatment burden score was significantly higher when patients experienced medication side effects $(P<0.0001)$ and for patients whose treatment did not relieve their symptoms $(P<0.0001)$.

We found a moderate agreement (ICC 0.60 (0.28 to $0.79)$ ) between patient and informal caregiver global scores (39 informal caregivers (7.8\%) completed the questionnaire) (Additional file 7, Appendix 7a). Bland and Altman plots showed a mean difference of -8.7 ; 95\% limits of agreement were -58.0 and 40.7 (Additional file 7, Appendix 7b). Agreement between patient and physician global scores was weak (ICC 0.38 (0.29 to 0.47)) (396 physicians $(78.9 \%)$ completed the questionnaire) (Additional file 8, Appendix 8). Bland and Altman plot showed a mean difference of -7.6 ; $95 \%$ limits of agreement were -60.7 and 45.4 (Figure 2). Agreement between patient and general practitioner $(\mathrm{n}=209)$ evaluations was ICC $=$ $0.42(0.27$ to 0.54$)$. Agreement between patient and hospital specialists $(\mathrm{n}=187)$ evaluations was $\mathrm{ICC}=0.29$ (0.14 to 0.42) (Additional file 9, Appendix 9). Treatment workload variables could explain up to $76 \%$ of the variation in physician evaluations and was more accurate for patients with high than low treatment burden $\left(R^{2}=0.82\right.$ vs $\mathrm{R}^{2}=0.72$ ) (Additional file 6, Appendix 6).

Retests were obtained for 211 patients (42.0\%). For the global score, the ICC for all retests was 0.76 (0.67 to 0.83$)$

Table 2 Items of the final Treatment Burden Questionnaire

\begin{tabular}{|c|c|}
\hline $\begin{array}{l}\text { Item } \\
\text { no. }\end{array}$ & Item \\
\hline $1 \mathrm{~A}$ & The taste, shape or size of your tablets and/or the inconvenience caused by your injections (for example, pain, bleeding, scars) \\
\hline $1 \mathrm{~B}$ & The number of times you have to take your medication every day \\
\hline $1 \mathrm{C}$ & The things you do to remind yourself to take your daily medication and/or to manage your treatment when you are not at home \\
\hline 1D & $\begin{array}{l}\text { The specific conditions when taking your medication (for example, taking it at a specific time of the day or meal, not being able to do } \\
\text { certain things after taking them like driving or lying down) }\end{array}$ \\
\hline $2 \mathrm{~A}$ & Lab tests and other exams (frequency, time spent and inconvenience of these exams) \\
\hline 2B & $\begin{array}{l}\text { Self-monitoring (for example, taking your blood pressure or measuring your blood sugar yourself: frequency, time spent and } \\
\text { inconvenience of this surveillance) }\end{array}$ \\
\hline $2 \mathrm{C}$ & Doctors visits (frequency and time spent for the visits) \\
\hline $2 \mathrm{D}$ & Arrange appointments and schedule doctors visits and lab tests \\
\hline 3 & $\begin{array}{l}\text { How would you rate the burden associated with taking care of paperwork from health insurance agencies, welfare organizations, hospitals } \\
\text { and/or social care? }\end{array}$ \\
\hline 4 & How would you rate the constraints associated with your diet (for example, not being allowed to eat certain foods)? \\
\hline 5 & How would you rate the burden associated with the recommendations from your doctors to practice regular physical exercises? \\
\hline 6 & $\begin{array}{l}\text { What is the impact of your healthcare on your social relationships (for example, need for assistance, being ashamed to take your } \\
\text { medication in front of people)? }\end{array}$ \\
\hline 7 & 'Frequent healthcare reminds me of my health problems' \\
\hline
\end{tabular}



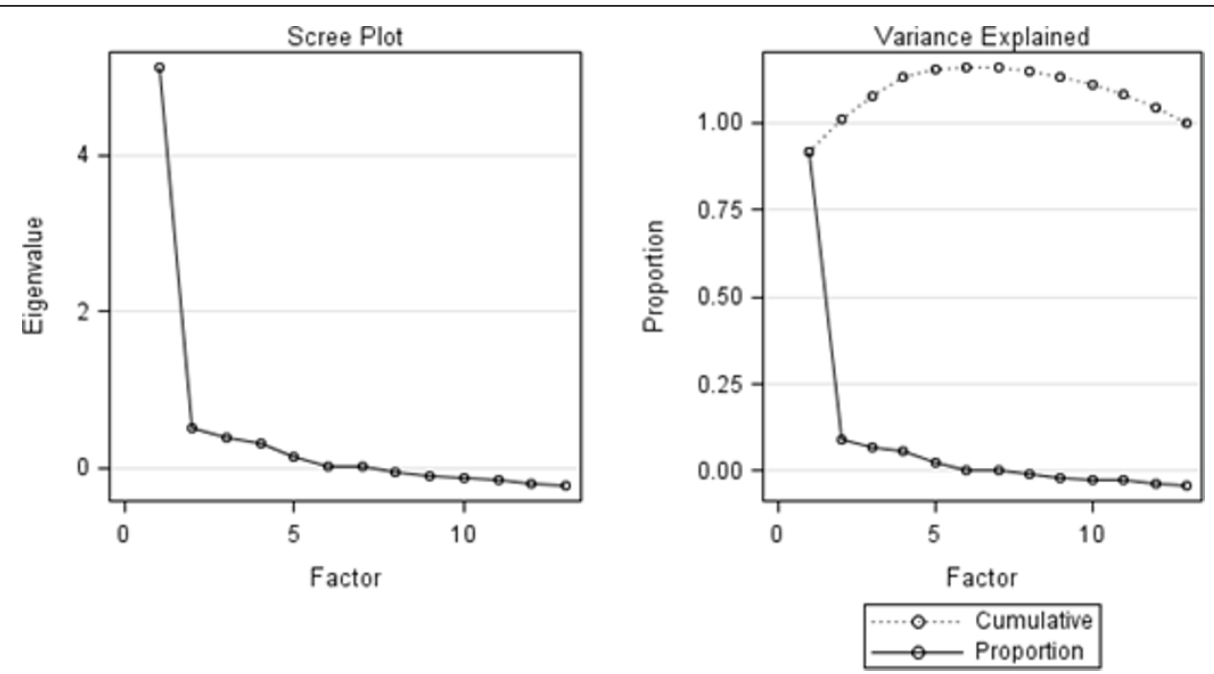

Figure 1 Eigenvalue diagram of the factor analysis of the questionnaire for treatment burden. The scree plot shows a break before factor 2, which suggests a unidimensional solution. 'Does not apply' was considered the lowest possible score (0).

(Additional file 10, Appendix 10a). Bland and Altman plots showed a mean difference of $-5.9 ; 95 \%$ limits of agreement were -42.4 and 30.5 (Additional file 10, Appendix 10b). Reliability for the 2 -week retest group $(n=182)$ was consistent with the 1 -month retest group $(\mathrm{n}=29)$ (ICC $=0.75$ (0.65 to 0.83$)$ vs ICC $=0.78$ (0.46 to 0.91$)$ ).

\section{Discussion}

In this study, we presented a unidimensional valid and reliable instrument assessing the treatment burden of chronic diseases for patients with multiple chronic conditions. This patient-reported measure took into account the burden associated with drug intake, surveillance, lifestyle changes and the impact of healthcare on social relationships.

The instrument could help in clinical research for developing clinical practice guidelines adapted to the realities of patient lives. In addition, it could be used in clinical practice as a validated global score that is easy to calculate to identify patients overwhelmed by their treatment to help begin conversations about treatment burden with these patients.
We highlighted a negative correlation between treatment burden and treatment satisfaction: the more satisfied patients were with their treatment, the less the treatment burden. We expected that our scale score would correlate highly with the TSQM convenience score because some items overlapped. However, patients with side effects and who found the treatment inefficient would feel less agreeable to integrate the treatment in their lives.

Treatment burden did not concern only patients taking a lot of medications: $25 \%$ of patients in our sample took $<3$ medications a day and still had a median treatment burden score of 17 (Q1 to Q3: 6 to 36). Therefore, treatment burden should be taken into account for every patient, because it could be associated with adherence to care [9] and thus could contribute to hospitalizations and survival rates [11]. However, physicians were often not fully aware of their patients' investment of time and efforts to comply with every prescription: we found only weak agreement between evaluation of treatment burden between patients and physicians. Even for specific domains such as self-monitoring or the prescription of a diet, physicians could not predict their patient's

Table 3 Relationship between the Treatment Satisfaction Questionnaire for Medication (TSQM) scores and Treatment Burden Questionnaire global score ( $\mathrm{n}=502$ patients)

\begin{tabular}{lll}
\hline & Correlation with the Treatment Burden Questionnaire global score & $\boldsymbol{P}^{\mathrm{a}}$ value \\
\hline TSQM global score & -0.41 & $<0.0001$ \\
\hline TSQM efficacy score & -0.26 & $<0.0001$ \\
\hline TSQM convenience score & -0.53 & $<0.0001$ \\
\hline TSQM side effects score & -0.52 & $<0.0001$ \\
\hline
\end{tabular}

The TSQM assesses satisfaction with medication. Scores range from 0 to 100 . A high score indicates high satisfaction with the medication. Negative coefficients indicate a decrease in the TSQM score associated with an increase in treatment burden.

${ }^{a}$ TSQM side effects score was calculated only for patients who declared experiencing side effects. 
Table 4 Relationship between treatment workload variables and the Treatment Burden Questionnaire global score (n = 502 patients).

\begin{tabular}{|c|c|c|c|c|}
\hline & $\begin{array}{l}\text { Correlation with the Treatment } \\
\text { Burden Questionnaire global score }\end{array}$ & No. (\%) & $\begin{array}{l}\text { Mean } \\
\text { score }\end{array}$ & $P$ value \\
\hline \multicolumn{5}{|l|}{ Correlation with treatment workload continuous variables } \\
\hline Number of hospitalizations during the last year & 0.24 & - & - & $<0.0001$ \\
\hline Number of medical appointments/month & 0.28 & - & - & $<0.0001$ \\
\hline Number of different physicians & 0.29 & - & - & $<0.0001$ \\
\hline Total number of tablets/day & 0.25 & - & - & $<0.0001$ \\
\hline Total number of injections/day & 0.31 & - & - & $<0.0001$ \\
\hline Number of drug intakes/day & 0.16 & - & - & 0.0004 \\
\hline $\begin{array}{l}\text { Time needed for healthcare per week (sum of the time needed for } \\
\text { surveillance and the time needed to organize the treatment) }\end{array}$ & 0.4 & - & - & $<0.0001$ \\
\hline \multicolumn{5}{|c|}{ Comparison between groups defined by treatment workload qualitative variables } \\
\hline \multicolumn{5}{|c|}{ Need for a specific organization for daily care: } \\
\hline Yes & - & $338(67.3 \%)$ & 34.41 & \\
\hline No & & $164(32.7 \%)$ & 23.85 & $<0.0001$ \\
\hline \multicolumn{5}{|l|}{ Need for self-monitoring: } \\
\hline Yes & - & $168(33.5 \%)$ & 41.24 & $<0.0001$ \\
\hline No & & $334(66.5 \%)$ & 25.79 & \\
\hline \multicolumn{5}{|l|}{ Diet: } \\
\hline Yes & - & $198(40.3 \%)$ & 38.34 & $<0.0001$ \\
\hline No & & $293(59.7 \%)$ & 26.01 & \\
\hline \multicolumn{5}{|l|}{ Physical therapy: } \\
\hline Yes & - & $113(22.9 \%)$ & 35.77 & \\
\hline No & & $380(77.1 \%)$ & 29.73 & 0.02 \\
\hline \multicolumn{5}{|l|}{ Oxygen therapy: } \\
\hline Yes & - & $22(4.4 \%)$ & 44.68 & \\
\hline No & & $476(94.8 \%)$ & 30.47 & 0.005 \\
\hline Presence of side effects: & - & & & \\
\hline Yes & & $168(36.3 \%)$ & 42.07 & $<0.0001$ \\
\hline No & & $295(63.7 \%)$ & 25.08 & \\
\hline \multicolumn{5}{|l|}{ The patient considers treatment as efficient: } \\
\hline Yes & - & $317(63.1 \%)$ & 27.35 & $<0.0001$ \\
\hline No & & $185(36.8 \%)$ & 37.13 & \\
\hline
\end{tabular}

Spearman correlation coefficient for continuous variables and two-sided Wilcoxon two-sample test for qualitative variables

${ }^{a}$ Global score is the sum of all items scores of the questionnaire with 'Does not apply' and missing answers considered as the lowest possible score (0).

evaluation. General practitioners, who are coordinators of care in France, have better knowledge than hospital specialists of how patients cope with everything they do to take care of their health (ICC $=0.42$ for general practitioners and 0.20 for hospital specialists) but still fail to assess patients' treatment burden accurately. This finding is not unexpected, because treatment burden is a relatively new concept to physicians [13] and expresses a patient experience that is not shared in depth during consultations [36].

In existing questionnaires, treatment burden was often considered only as a subscale for larger disease-specific scales $[16,17]$ and focused on a single treatment regimen. Given the increasing number of patients with multiple chronic diseases and complex treatment regimens, measuring global treatment burden seems increasingly important. As Gallacher et al. have shown for chronic heart failure, treatment burden relates to how patients cope with their treatment [37]: (1) learning about treatment and their consequences, (2) monitoring the treatment, (3) adhering to treatment and lifestyle changes and (4) engaging with others. During our study, we asked patients about aspects of their healthcare that were not mentioned in our questionnaire but had an impact on their lives. We found the same domains of treatment burden as Gallacher et al., with the exception of gaining an understanding about illness and treatments. Nevertheless, acquiring this knowledge is an important burden in the management of chronic conditions, especially when patients have to make sense of the disparate and conflicting information they gather from different sources. However, because we recruited patients with illnesses for at 
Table 5 Characteristics of groups clustered by the hierarchical ascendant classification ( $\mathbf{n}=\mathbf{5 0 2}$ patients)

\begin{tabular}{|c|c|c|c|c|c|}
\hline Characteristic & $\begin{array}{l}\text { Whole sample } \\
(n=502)\end{array}$ & $\begin{array}{l}\text { 'Low burden' } \\
(\mathrm{n}=240)\end{array}$ & $\begin{array}{l}\text { 'Moderate burden' } \\
(n=140)\end{array}$ & $\begin{array}{l}\text { 'High burden' } \\
(n=122)\end{array}$ & $P$ value \\
\hline Global score & $30.1 \pm 25.3$ & $11.3 \pm 9.2$ & $34.6 \pm 11.1$ & $65.8 \pm 18.1$ & $<0.0001$ \\
\hline Age, years & $59.3 \pm 17.0$ & $62.9 \pm 16.1$ & $59.2 \pm 17.9$ & $52.2 \pm 15.6$ & $<0.0001$ \\
\hline Female sex, no. (\%) & 266 & $118(49.2 \%)$ & $78(55.7 \%)$ & $70(57.8 \%)$ & 0.23 \\
\hline Marital status & & & & & 0.19 \\
\hline Married & 216 & $105(45.3 \%)$ & $60(43.5 \%)$ & $51(42.9 \%)$ & \\
\hline Live in partner & 38 & $13(5.6 \%)$ & $12(8.7 \%)$ & $13(10.9 \%)$ & \\
\hline Single/separated & 171 & $76(32.8 \%)$ & 49 (35.5\%) & $46(38.7 \%)$ & \\
\hline Widowed & 64 & $38(16.4 \%)$ & $17(12.3 \%)$ & $9(7.6 \%)$ & \\
\hline Highest education level, no. (\%) & & & & & 0.76 \\
\hline No diploma/primary school & 85 & $43(19.9 \%)$ & $23(17.6 \%)$ & 19 (17.1\%) & \\
\hline Secondary/high school & 195 & $96(44.4 \%)$ & $54(41.2 \%)$ & $45(40.5 \%)$ & \\
\hline College & 178 & 77 (35.6\%) & $54(41.2 \%)$ & $47(42.3 \%)$ & \\
\hline Inpatient, no. (percentage of the whole sample) & 257 & $105(43.7 \%)$ & $84(60.0 \%)$ & $68(55.7 \%)$ & 0.004 \\
\hline Duration of disease, years & $15.0 \pm 15.4$ & $16.3 \pm 16.5$ & $14.5 \pm 16.7$ & $13.3 \pm 10.7$ & 0.34 \\
\hline Presence of daily symptoms & 300 & $110(48.0 \%)$ & $93(70.4 \%)$ & $97(82.2 \%)$ & $<0.0001$ \\
\hline Need for assistance, no. (\%) & 132 & $45(18.8 \%)$ & $41(29.3 \%)$ & $46(38.0 \%)$ & 0.0003 \\
\hline Number of hospitalizations during the last 12 months & $1.1 \pm 1.9$ & $0.9 \pm 1.8$ & $1.2 \pm 1.9$ & $1.5 \pm 2.1$ & 0.0004 \\
\hline Number of medical appointments/month & $2.3 \pm 3.4$ & $1.5 \pm 1.6$ & $2.6 \pm 3.3$ & $3.6 \pm 5.2$ & $<0.0001$ \\
\hline Number of different physicians & $2.4 \pm 1.4$ & $2.1 \pm 1.3$ & $2.4 \pm 1.3$ & $2.9 \pm 1.4$ & $<0.0001$ \\
\hline Number of tablets/day & $5.4 \pm 4.5$ & $4.5 \pm 4.1$ & $5.7 \pm 3.9$ & $7.0 \pm 5.5$ & $<0.0001$ \\
\hline Number of drug intakes/day & $1.9 \pm 1.0$ & $1.8 \pm 1.0$ & $2.0 \pm 1.0$ & $2.1 \pm 1.1$ & 0.07 \\
\hline Number of injections/day & $0.5 \pm 1.3$ & $0.2 \pm 0.9$ & $0.3 \pm 0.9$ & $1.3 \pm 1.9$ & $<0.0001$ \\
\hline Diet, no. (\%) & 198 & 75 (31.9\%) & $57(42.2 \%)$ & $66(54.5 \%)$ & 0.0002 \\
\hline Physical therapy, no. (\%) & 113 & $45(19.2 \%)$ & $33(23.9 \%)$ & $35(28.9 \%)$ & 0.11 \\
\hline Oxygen therapy, no. (\%) & 22 & $5(2.1 \%)$ & $8(5.7 \%)$ & $9(7.4 \%)$ & 0.05 \\
\hline Time needed to organize drugs/week* & $22 \pm 92 \min$ & $17 \pm 100 \mathrm{~min}$ & $13 \pm 51 \min$ & $43 \pm 108 \mathrm{~min}$ & $<0.0001$ \\
\hline Need for self-monitoring, no. (\%) & 168 & $61(25.4 \%)$ & $36(25.7 \%)$ & $71(58.2 \%)$ & $<0.0001$ \\
\hline Time needed for self-monitoring/week* & $14 \pm 66 \min$ & $5 \pm 31 \mathrm{~min}$ & $10 \pm 67 \min$ & $37 \pm 101 \mathrm{~min}$ & $<0.0001$ \\
\hline Presence of side effects, no. (\%) & 168 & $46(20.9 \%)$ & $56(43.1 \%)$ & $66(58.4 \%)$ & $<0.0001$ \\
\hline Patient considers his treatment efficient, no. (\%) & 317 & $176(73.3 \%)$ & $74(52.9 \%)$ & $67(54.9 \%)$ & $<0.0001$ \\
\hline Main chronic condition, no. (\%) & & & & & $<0.0001$ \\
\hline Diabetes & 81 & $25(10.7 \%)$ & $14(10.1 \%)$ & $42(35.0 \%)$ & \\
\hline Rheumatologic diseases & 59 & $25(10.7 \%)$ & $21(15.2 \%)$ & $13(10.8 \%)$ & \\
\hline Pulmonary diseases (other than asthma) & 40 & $23(9.9 \%)$ & $12(8.7 \%)$ & $5(4.2 \%)$ & \\
\hline High blood pressure and dyslipidemia & 44 & $29(12.4 \%)$ & $9(6.5 \%)$ & $6(5.0 \%)$ & \\
\hline Asthma & 37 & $23(9.9 \%)$ & $8(5.8 \%)$ & $6(5.0 \%)$ & \\
\hline Systemic diseases & 43 & $16(6.9 \%)$ & $13(9.4 \%)$ & $14(11.7 \%)$ & \\
\hline
\end{tabular}

Patients were clustered in three groups depending on the similarity of their responses to the instrument. Global score was $11.3( \pm 9.2)$ in the first cluster, $34.6( \pm$ $11.1)$ in the second cluster and $65.8( \pm 18.1)$ in the third cluster. Therefore, we defined the clusters as patients with low, moderate and high burden of treatment. Continuous variables are presented as mean $\pm \mathrm{SE}$. Categorical variables are presented as proportion of the corresponding subgroup. Associations between continuous variables among different classes were determined by Wilcoxon test. Qualitative variables are presented by their frequency in the whole sample. Associations between qualitative variables among different classes were determined by the $\chi^{2}$ test. Global score is the sum of all items scores of the questionnaire with 'Does not apply' and missing answers considered the lowest possible score (0).

*Time needed for patients who did not require specific organization for daily care or who had no self-monitoring was considered 0 .

least 6 months, they might have already coped with this particular burden, adapted to it, and therefore did not mention it.

The strengths of this study included field testing the instrument in a large sample of both inpatients and outpatients with different conditions and treatment regimens, which ensured that our instrument was flexible enough for assessing the treatment burden across any disease or context. However, we found a significant floor effect and a large proportion of 'Does not apply' responses for all of our scales. This result was expected because treatment burden depends on how patients cope with their treatment regimens. Therefore, patients could have no burden in aspects of their care they have 


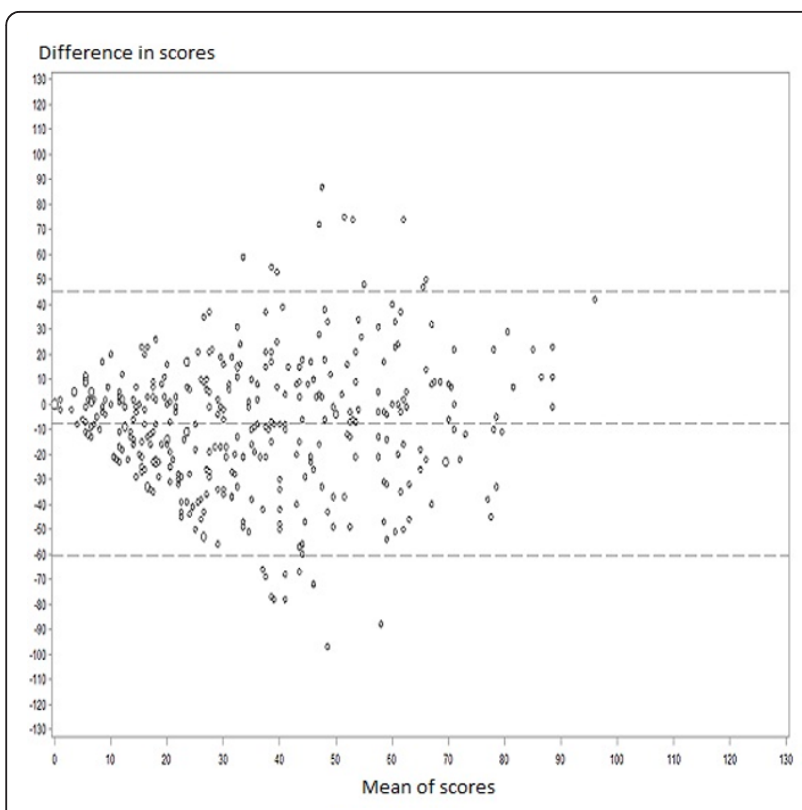

Figure 2 Bland and Altman plot representing agreement between Treatment Burden Questionnaire global scores for patients and physicians ( $\mathbf{n}=\mathbf{3 9 6}$ patients). The difference between global score for patients and physicians is plotted against the mean score. Negative differences mean that physicians overestimated the burden and positive differences that they underestimated it. Horizontal lines are drawn at the mean difference between the two

measurements and the upper and lower limits of agreement. The size of markers reflects the number of individual observations.

integrated in their lives. As well, patients with similar treatment regimens could have very different treatment burdens. Still, domains not included in this instrument may be critical to some of these patients. During the validation study, we systematically searched for other aspects of treatment burden that could have an impact on patients' quality of life but found no preeminent domain.

More work in measuring treatment burden is needed. Because treatment burden depends on the context of patients (social or family structure, care delivery system) [13] and because our instrument was developed in France, we could not exclude that different domains could arise in other settings. As an example, the financial burden of the treatment did not arise from our qualitative interviews because the public health insurance program in France guarantees healthcare free of charge for patients with chronic conditions. In addition, depending on the social or family structure, the treatment burden may be shared by the patient with one or more informal caregivers, thus affecting the validity of the measure when only reported by the patient.

\section{Conclusions}

Our instrument on treatment burden for patients exhibiting multiple chronic conditions provides the first valid and reliable solution to assess the burden of treatment across any disease or treatment context. It may help in the development of treatment strategies that are both efficient and acceptable for patients.

\section{Additional material}

Additional file 1: Appendix 1. Demographic and clinical characteristics of patients included in the semistructured interview pretest $(n=22)$.

Additional file 2: Appendix 2. Characteristics of the items presented to patients ( $n=502$ patients).

Additional file 3: Appendix 3. Eigenvalues for the correlation matrix. Additional file 4: Appendix 4. Association of items of the Treatment Burden Questionnaire and global score ( $n=502$ patients).

Additional file 5: Appendix 5. Dendogram of the hierarchical ascendant classification of patients by their answers to the Treatment Burden Questionnaire ( $n=502$ patients).

Additional file 6: Appendix 6. (a). Linear regression analysis of relation between global score for Treatment Burden Questionnaire as assessed by patients with variables associated with treatment workload. (b) Linear regression analysis of relation between global score for Treatment Burden Questionnaire as assessed by physicians with variables associated with treatment workload.

Additional file 7: Appendix 7. (a) Agreement between patients and informal caregiver evaluations of the treatment burden $(n=39)$. (b) Bland and Altman plot representing agreement between Treatment Burden Questionnaire global scores for patients and informal caregivers ( $n=39$ ).

Additional file 8: Appendix 8. Agreement between patients and physician evaluations of the treatment burden $(n=396)$.

Additional file 9: Appendix 9. Validation of the instrument in different subgroups.

Additional file 10: Appendix 10. (a) Reliability using test-retest ( $\mathrm{n}=$ 211). (b) Bland and Altman plot representing the test-retest reliability of the Treatment Burden Questionnaire global score $(n=211)$.

\section{Acknowledgements}

The authors thank Michel Nougairède, Anna Christidis, Gaële Duriez-Mize, Marie-Anne Puel, Philippe Fabri, Ismael Nureni-Banafunzi, Elena Kisseleva, Gilbert Dhumerelle, Anne Simon, Serge Herson, Jacques Blacher, Christian Boitard, Gérard Huchon, Jean-François Bergmann, Alain Cohen-Solal, Olivier Meyer, Serge Poiraudeau and Loïc Guillevin for permission to collect data; Clémence Palazzo for assistance in data acquisition; Gabriel Baron and VietChi Tran for help in the analysis of the data; and Laura Smales for reviewing the manuscript before submission.

The $\mathrm{TBQ}^{\odot}$ is protected by international copyright, with all rights reserved to $P R$ and $V-T T$. For information on, or permission to use, the TBQ, please contact PROinformation@mapi-trust.org http://www.mapi-trust.org. This study was partly funded by INSERM U738, Paris, France.

\section{Author details}

${ }^{1}$ Université Paris Descartes, Faculté de Médecine, Paris, France. ${ }^{2}$ INSERM U738, Paris, France. ${ }^{3}$ Division of Health Care and Policy Research, Department of Health Sciences Research and Knowledge and Evaluation Research Unit, Mayo Clinic, Rochester, MN, USA. ${ }^{4}$ Université Paris DenisDiderot, Faculté de Médecine, Paris, France. ${ }^{5}$ INSERM U669, Paris, France. ${ }^{6}$ Université Paris Sud, Paris, France. ${ }^{7}$ Department of Epidemiology, Columbia University Mailman School of Public Health, New York, NY, USA.

\section{Authors' contributions}

$\mathrm{V}-T \mathrm{~T}, \mathrm{BF}$ and PR conceived and designed the study. $\mathrm{V}-T \mathrm{~T}$ and $\mathrm{DB}$ acquired the data. V-TT, BF, PR analyzed and interpreted the data. $V$-TT and PR drafted the manuscript. VM, BF, DE, DB and PR critically revised the manuscript for 
important intellectual content. DB and PR provided administrative, technical, and material support. All authors saw and approved the final manuscript. PR is the guarantor, had full access to the data in the study, and takes responsibility for the integrity of the data and the accuracy of the data analysis.

\section{Competing interests}

The authors declare that they have no competing interests.

Received: 13 January 2012 Accepted: 4 July 2012 Published: 4 July 2012

\section{References}

1. Alwan A: Global Status Report on Noncommunicable Diseases 2010 Geneva, Switzerland: World Health Organization; 2011.

2. Wolff $J$, Starfield B, Anderson G: Prevalence, expenditures, and complications of multiple chronic conditions in the elderly. Arch Intern Med 2002, 162:2269-2276.

3. Tinetti ME, Fried T: The end of the disease era. Am J Med 2004, 116:179-185.

4. Boyd CM, Darer J, Boult C, Fried LP, Boult L, Wu AW: Clinical practice guidelines and quality of care for older patients with multiple comorbid diseases: implications for pay for performance. JAMA 2005, 294:716-724.

5. Russell LB, Suh DC, Safford MA: Time requirements for diabetes selfmanagement: too much for many? J Fam Pract 2005, 54:52-56.

6. Huang ES, Brown SE, Ewigman BG, Foley EC, Meltzer DO: Patient perceptions of quality of life with diabetes-related complications and treatments. Diabetes Care 2007, 30:2478-2483.

7. Eton DT, Mullan RJ, Yost KJ, Egginton J, Ridgeway J, Fields HE, Mustafa M, Schmit K, Erwin PJ, Murad H, Montori VM: A systematic review of burden of treatment instruments in three chronic diseases. Int Soc Qual Life Res 2011, 86(Suppl), ab. 294.

8. Eton DT, Oliveira DR, Egginton J, Mair FS, May C, Montori VM: Understanding the burden of treatment in patients with multiple chronic conditions: Evidence from exploratory interviews. Qual Life Res 2010, 19(Suppl 1), ab. 1673.

9. Vijan S, Hayward RA, Ronis DL, Hofer TP: Brief report: the burden of diabetes therapy: implications for the design of effective patientcentered treatment regimens. J Gen Intern Med 2005, 20:479-482.

10. Vermeire $E$, Hearnshaw $H$, Van Royen P, Denekens J: Patient adherence to treatment: three decades of research. A comprehensive review. J Clin Pharm Ther 2001, 26:331-342.

11. Ho PM, Rumsfeld JS, Masoudi FA, McClure DL, Plomondon ME, Steiner JF, Magid DJ: Effect of medication nonadherence on hospitalization and mortality among patients with diabetes mellitus. Arch Intern Med 2006, 166:1836-1841.

12. Rasmussen JN, Chong A, Alter DA: Relationship between adherence to evidence-based pharmacotherapy and long-term mortality after acute myocardial infarction. JAMA 2007, 297:177-186.

13. May C, Montori VM, Mair FS: We need minimally disruptive medicine. BMJ 2009, 339:b2803.

14. Wilcox AR, Dragnev MC, Darcey CJ, Siegel CA: A new tool to measure the burden of Crohn's disease and its treatment: do patient and physician perceptions match? Inflamm Bowel Dis 2010, 16:645-650.

15. Liu JY, Woloshin S, Laycock WS, Rothstein RI, Finlayson SR, Schwartz LM: Symptoms and treatment burden of gastroesophageal reflux disease: validating the GERD assessment scales. Arch Intern Med 2004, 164:2058-2064.

16. Brod M, Hammer M, Kragh N, Lessard S, Bushnell DM: Development and validation of the Treatment Related Impact Measure of Weight (TRIMWeight). Health Qual Life Outcomes 2010, 8:19.

17. Brod M, Hammer M, Christensen T, Lessard S, Bushnell DM: Understanding and assessing the impact of treatment in diabetes: the TreatmentRelated Impact Measures for Diabetes and Devices (TRIM-Diabetes and TRIM-Diabetes Device). Health Qual Life Outcomes 2009, 7:83.

18. Prins MH, Guillemin I, Gilet H, Gabriel S, Essers B, Raskob G, Kahn SR: Scoring and psychometric validation of the Perception of Anticoagulant Treatment Questionnaire (PACT-Q). Health Qual Life Outcomes 2009, 7:30.

19. Falissard B: Mesurer la subjectivité en santé. Perspective méthodologique et statistique Paris, France: Masson; 2001.

20. Guyatt $\mathrm{GH}$, Bombardier C, Tugwell PX: Measuring disease-specific quality of life in clinical trials. CMAJ 1986, 134:889-895.
21. Terwee CB, Bot SD, De Boer MR, Van der Windt DA, Knol DL, Dekker J, Bouter LM, De Vet HC: Quality criteria were proposed for measurement properties of health status questionnaires. J Clin Epidemiol 2007, 60:34-42.

22. Frisbie D, Brandenburg D: Equivalence of questionnaire items with varying response formats. J Educ Meas 1979, 16:43-48.

23. Wildt A, Mazis A: Determinant of scale response: label versus position. $J$ Marketing Res 1978, 15:261-267.

24. Schwarz N, Knauper B, Hippler H, Noelle-Neumann E, Clark L: Rating scales: Numeric values may change the meaning of scale labels. Public Opin Quart 1991, 55:570-582.

25. Cronbach L: Coefficient alpha and the internal structure of tests. Psychometrika 1951, 16:297-334.

26. Nunnaly J, Bernstein I: Psychometric Theory New York, USA: McGraw-Hill; 1994.

27. Streiner D, Norman G: Health Measurement Scales: A Practical Guide to Their Development and Use Oxford, UK: Oxford University Press; 2008.

28. Atkinson MJ, Sinha A, Hass SL, Colman SS, Kumar RN, Brod M, Rowland CR: Validation of a general measure of treatment satisfaction, the Treatment Satisfaction Questionnaire for Medication (TSQM), using a national panel study of chronic disease. Health Qual Life Outcomes 2004, 2:12.

29. Atkinson MJ, Kumar R, Cappelleri JC, Hass SL: Hierarchical construct validity of the treatment satisfaction questionnaire for medication (TSQM version II) among outpatient pharmacy consumers. Value Health 2005, 8(Suppl 1):S9-S24.

30. Juniper $E$, Guyatt $G$, Jaeschke R: How to develop and validate a new health-related quality of life instrument. Quality of Life and Pharmacoeconomics in Clinical Trials New York, USA: Raven Press; 1996, 49-56.

31. Greene W: Econometric Analysis New York, USA: Macmillan; 2000.

32. Joe $H$, Ward J: Hierarchical grouping to optimize an objective function. J Am Stat Assoc 1963, 58:236-244.

33. Shrout PE, Fleiss JL: Intraclass correlations: uses in assessing rater reliability. Psychol Bull 1979, 86:420-428.

34. Lohr KN: Assessing health status and quality-of-life instruments: attributes and review criteria. Qual Life Res 2002, 11:193-205.

35. Bland JM, Altman DG: Measuring agreement in method comparison studies. Stat Methods Med Res 1999, 8:135-160.

36. Bohlen K, Scoville E, Shippee ND, May CR, Montori VM: Overwhelmed patients: a videographic analysis of how patients with type 2 diabetes and clinicians articulate and address treatment burden during clinical encounters. Diabetes Care 2012, 35:47-49.

37. Gallacher K, May CR, Montori VM, Mair FS: Understanding patients' experiences of treatment burden in chronic heart failure using normalization process theory. Ann Fam Med 2011, 9:235-243.

Pre-publication history

The pre-publication history for this paper can be accessed here: http://www.biomedcentral.com/1741-7015/10/68/prepub

doi:10.1186/1741-7015-10-68

Cite this article as: Tran et al.: Development and description of measurement properties of an instrument to assess treatment burden among patients with multiple chronic conditions. BMC Medicine 2012 10:68.

\section{Submit your next manuscript to BioMed Central and take full advantage of:}

- Convenient online submission

- Thorough peer review

- No space constraints or color figure charges

- Immediate publication on acceptance

- Inclusion in PubMed, CAS, Scopus and Google Scholar

- Research which is freely available for redistribution

Submit your manuscript at www.biomedcentral.com/submit 